\title{
Self-Organized Perylene Diimide Nanofibers
}

Ping Yan, Arindam Chowdhury, Michael W. Holman and David M. Adams ${ }^{*}$

Department of Chemistry, Columbia University, New York, New York 10027

\section{Supporting Information}
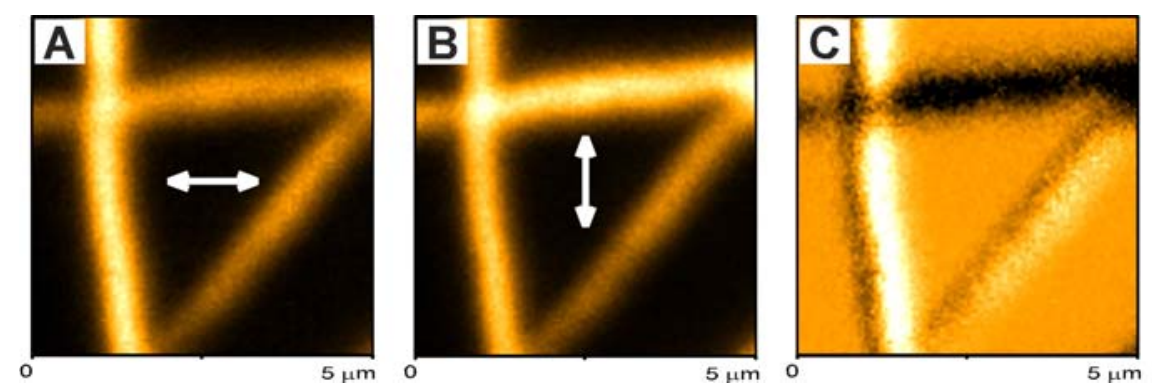

Figure S1. Polarized fluorescence from nanowires. A) Horizontally polarized and B) vertically polarized fluorescence images of self-organized nanowires upon excitation with circularly polarized laser. C) Difference image between B and C. 


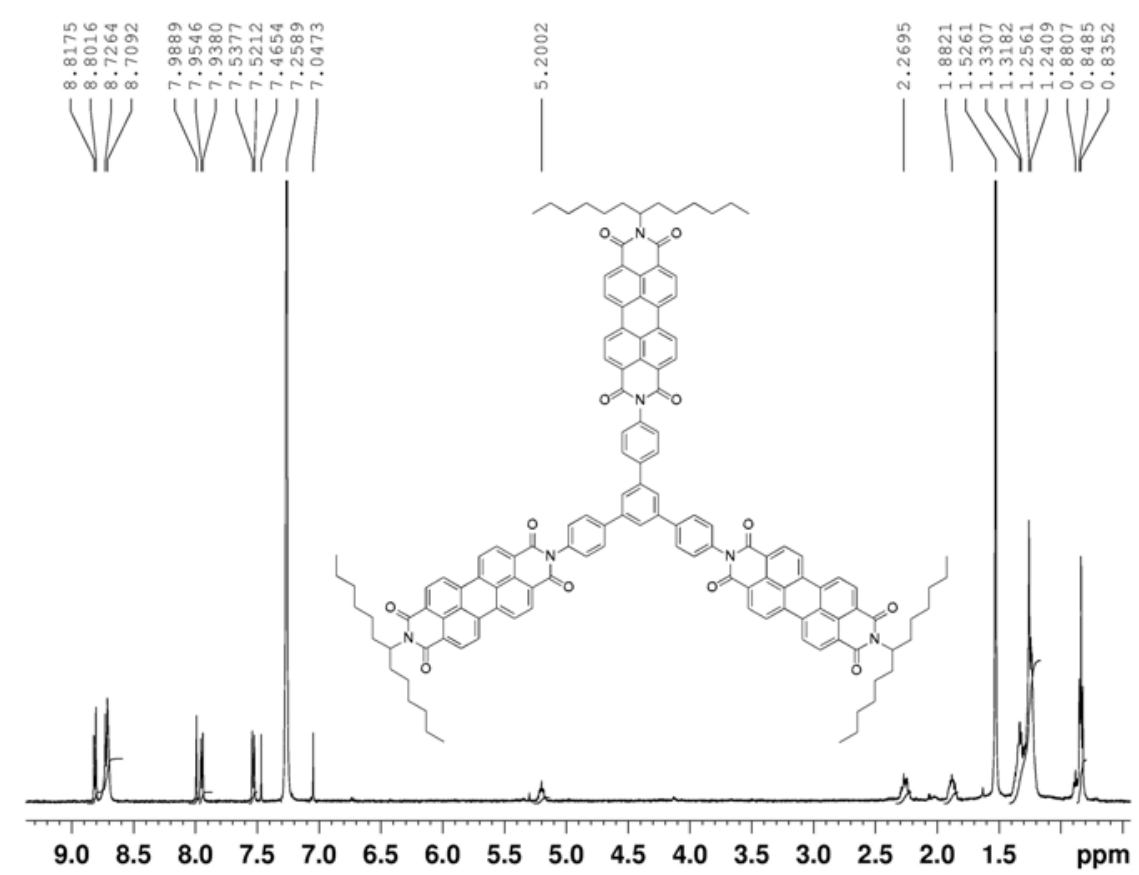

Figure S2. ${ }^{1} \mathrm{H}$ NMR $\left(500 \mathrm{MHz}, \mathrm{CDCl}_{3}\right)$ of $\mathbf{1}$.

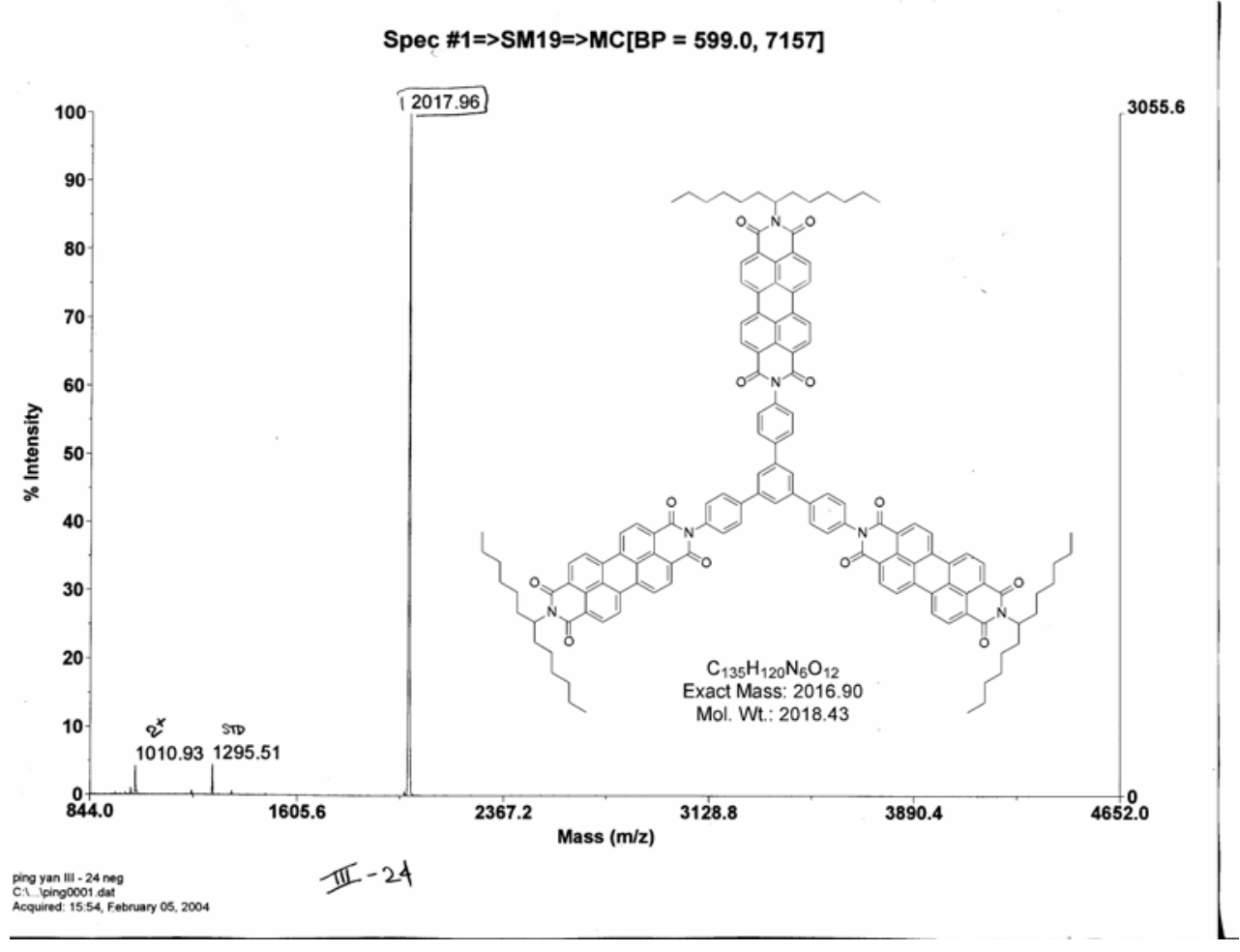

Figure S3. MS (MALDI, Negative) of $\mathbf{1}$. 